\title{
Takotsubo cardiomiopathy
}

The Takotsubo cardiomiopathy or stress cardiomyopathy is a rare disorder ${ }^{1-3}$ that occurs mostly in post-menopausal women ${ }^{1-4}$ in the context of a physical or emotional stress identified ${ }^{1-4}$, and that mimics the clinical, analytical, electrocardiographic and echocardiographic characteristics of an acute coronary syndrome ${ }^{1-4}$. Transient left ventricular dysfunction in the absence of obstructive coronary artery disease support its diagnosis ${ }^{1-4}$.

A 60-year-old woman without vascular risk factors previously known, with stage 3 chronic kidney disease and a history of diagnosis of Takotsubo cardiomiopathy without any identified stress factor. She was admitted to the emergency department for precordial chest pain described as weight, without irradiation, which worsened by deep inspiration, accompanied by nausea, with no other associated symptomatology. Electrocardiogram recorded in sinus rhythm, with complete right bundle branch block (previously known). Analyzes with elevation of myocardial necrosis markers (maximal troponin I of $4.63 \mathrm{ng} / \mathrm{ml}$ ). Transthoracic echocardiography revealed a non-dilated left ventricle with severe systolic dysfunction, maintaining only normal contraction of the basal segments. Coronary angiography without obstructive coronary artery disease and ventriculography with segmental alterations suggestive of Takotsubo cardiomyopathy (Figure 1). During hospitalization, she evolved to a stable condition, in Killip class 1, with electrical and hemodynamic stability. Electrocardiographic evolution with diffuse T-wave inversion. Transthoracic echocardiography of revaluation showed recovery of systolic function of the left ventricle. It was assumed Takotsubo cardiomiopathy recurrence in the absence of an identified stress event.

The Takotsubo cardiomiopathy mimics acute coronary syndrome ${ }^{1-4}$, so it should be considered in the differential diagnosis of acute coronary syndrome in order not to be underdiagnosed. For its diagnosis a high clinical suspicion is necessary (although in about $14-30 \%$ of the cases there is no triggering factor $^{1}$ as in the clinical case) and the availability of technical resources to perform complementary diagnostic tests that demonstrate transient ventricular dysfunction and absence of obstructive coronary artery disease ${ }^{1-4}$. This clinical entity usually has a benign course ${ }^{1-4}$ and rarely relapse ${ }^{1-3}$.

\section{References}

1. Mejía-Rentería HD, Núñez-Gil IJ. Takotsubo syndrome: Advances in the understanding and management of an enigmatic stress cardiomyopathy. World J Cardiol 2016;8:413-424.

2. Nuñez-Gil IJ, Luaces Mendéz M, García-Rubira JC. Cardiopatía de estrés o síndrome de Tako-Tsubo: conceptos actuales. Rev Argent Cardiol. 2009;77:218-223.

3. Sousa Torres JC, Birne RL, Assis Pereira T, Silva Sousa H, Calenga A, Branco P, et al. Takotsubo cardiomyopathy in patients undergoing haemodialysis - mini review apropos of a case. Port J Nephrol Hypert 2016;30:33-40.

4. Nóbrega S, Brito D. Miocardiopatia Takotsubo: estado da arte. Rev Port Cardiol. 2012;31:589-596.
Figure 1. Ventriculography (left ventricular in systole) - Segmental alterations suggestive of Takotsubo cardiomiopathy (anterior-apical and inferior akinesia, only contract the basal segments).

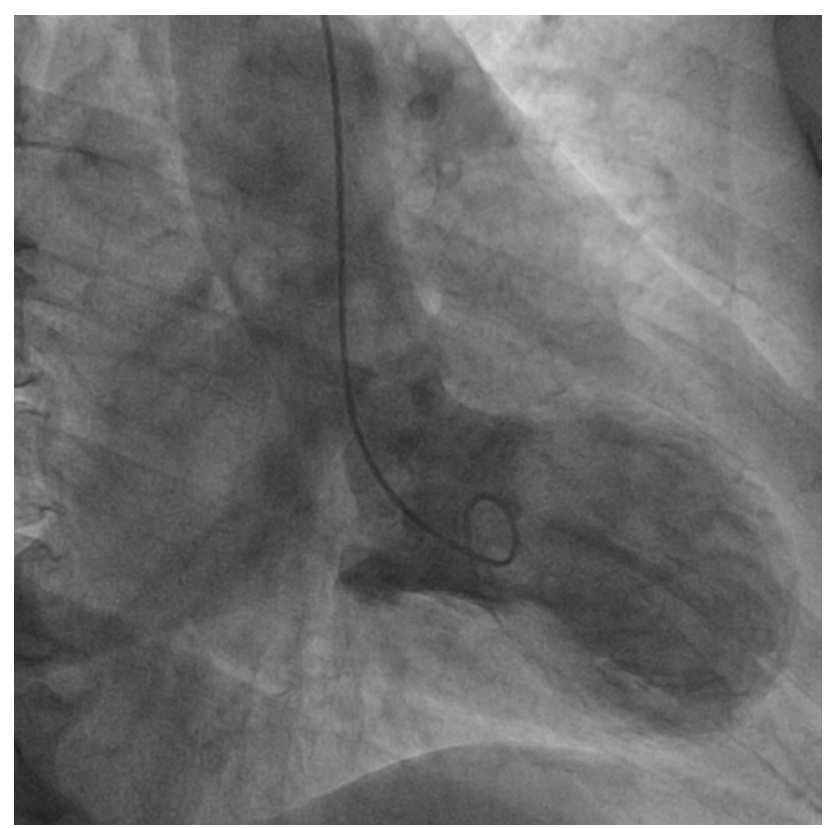

\section{Diagnosis: TakoTsubo cardiomiopathy}

\author{
Anabela Brito ${ }^{1}$, Paula Dias ${ }^{2}$ \\ IInternal Medicine Department, Hospital Conde de Bertiandos, \\ Unidade Local de Saúde do Alto Minho. Ponte de Lima, Portugal. \\ ${ }^{2}$ Cardiology Department, Hospital de São João, \\ Centro Hospitalar São João. Porto, Portugal.
}

Correspondencia: belanabrito@gmail.com

Cómo citar este artículo: Brito A, Dias P

Miocardiopatía de Takotsubo. Galicia Clin 2018; 79 (4): 146

Recibido: 30/01/2018; Aceptado: 15/02/2018 